\title{
Combined EUS LAMS and Percutaneous Fully Covered SEMS-Guided Direct Endoscopic Necrosectomy (e-DEN + p-DEN) for Walled-Off Pancreatic Necrosis with Paracolic Extension
}

\author{
Ashish Gandhi ${ }^{10}$ Mangesh Borkar ${ }^{1}$ Harsh Bapaye ${ }^{1,2(0}$ Rajendra Pujari ${ }^{1}$ Amol Bapaye ${ }^{10}$ \\ ${ }^{1}$ Shivanand Desai Centre for Digestive Disorders, Deenanath \\ Mangeshkar Hospital and Research Centre, Pune, Maharashtra, India \\ 2 Department of Medicine, Byramjee Jeejeebhoy Medical College, \\ Pune, Maharashtra, India

\begin{abstract}
Address for correspondence Amol Bapaye, MD (MS), FASGE, FJGES, FSGEI, Shivanand Desai Centre for Digestive Disorders, Deenanath Mangeshkar Hospital and Research Centre, Erandwane, Pune, Maharashtra, India (e-mail: amolbapaye@gmail.com).
\end{abstract}

\author{
Abstract \\ Keywords \\ - walled-off pancreatic \\ necrosis \\ - WON \\ - WOPN \\ - percutaneous direct \\ endoscopic \\ necrosectomy \\ - direct endoscopic \\ necrosectomy \\ - DEN \\ - DEN \\ - p-DEN
}

Management of infected lesser sac walled-off pancreatic necrosis (WOPN) is technically challenging and involves endoscopic ultrasound (EUS)-guided transmural drainage using either lumen-apposing metal stent (LAMS) or multiple plastic stents as the standard approach. A step-up approach-drainage followed by additional direct endoscopic necrosectomy (DEN) whenever required-has been a standard recommendation. Collections extending to the paracolic gutter are difficult to manage endoscopically and often require additional surgical intervention. In this video case, we describe a combined approach using EUS-guided LAMS and percutaneous fully covered self-expandable metal stent-guided DEN (e-DEN + p-DEN) for successful management of an infected lesser sac WOPN with paracolic extension.

\section{Introduction}

Management of infected walled-off pancreatic necrosis (WOPN) is technically challenging. Optimal endoscopic or surgical drainage with or without necrosectomy has been recommended. Endoscopic ultrasound (EUS)-guided transgastric or transduodenal placement of a lumen-apposing metal stent (LAMS) has been shown to be effective for drainage of WOPN in the lesser sac. Additional direct endoscopic necrosectomy (DEN) has been recommended whenever indicated for effective removal of solid necrotic debris from the collection. A "step-up" approach (drainage as the first step and additional DEN whenever required) has been recommended as the standard of care. ${ }^{1}$ WOPN extending into the left paracolic gutter are difficult to effectively drain endoscopically, especially because the paracolic extension is beyond the reach of the transgastric endoscope. Additional measures like percutaneous catheter drainage $(\mathrm{PCD})$, video-assisted retroperitoneal
DOI https://doi.org/ 10.1055/s-0041-1741388. ISSN 0976-5042. (c) 2022. Society of Gastrointestinal Endoscopy of India. All rights reserved.

This is an open access article published by Thieme under the terms of the Creative Commons Attribution-NonDerivative-NonCommercial-License, permitting copying and reproduction so long as the original work is given appropriate credit. Contents may not be used for commercial purposes, or adapted, remixed, transformed or built upon. (https://creativecommons.org/ licenses/by-nc-nd/4.0/)

Thieme Medical and Scientific Publishers Pvt. Ltd., A-12, 2nd Floor, Sector 2, Noida-201301 UP, India 


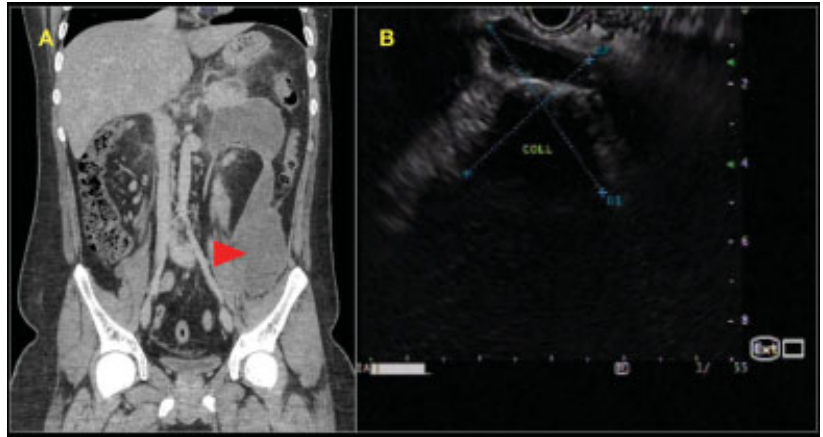

Fig. 1 (A) Contrast-enhanced computed tomography (CECT) abdomen coronal view demonstrating lesser sac and paracolic collection (red arrow). (B) Linear endoscopic ultrasound (EUS) showing multiloculated ill-defined necrotic collection with solid debris.

drainage (VARD), or surgery may therefore be required. However, VARD or surgery is associated with high morbidity and PCD is frequently inadequate for drainage. This video case demonstrates a combined EUS-LAMS and percutaneous selfexpandable metal stent (SEMS)-guided DEN (e-DEN + p-DEN) approach for successful management of an infected lesser sac WOPN with paracolic extension.

\section{Case Discussion}

An 18-year-old male patient presented with acute necrotizing pancreatitis and WOPN. Duration of illness was 6 weeks. Presenting symptoms were abdominal pain, fever, and failure to thrive. Laboratory investigations revealed total leucocyte count (TLC) $21,000 / \mathrm{mm}^{2}$. Contrast-enhanced computed tomography (CECT) scan of the abdomen revealed a large lesser sac peripancreatic fluid collection (size $95 \times 85 \times 270 \mathrm{~mm}$ ) with significant paracolic extension ( - Fig. 1A). EUS revealed a multiloculated poorly defined collection in the lesser sac with solid debris extending caudally into the left paracolic gutter (-Fig. 1B). A 24Fr PCD catheter was placed under USG guidance for the paracolic extension and EUS-guided transgastric drainage of the lesser sac collection was performed using a LAMS (Plumber stent 30 $\mathrm{mm} \times 16 \mathrm{~mm}$; MI Tech, South Korea) ( - Video 1 ). Patient's fever persisted, and therefore two DEN sessions (e-DEN) were performed using mixture of hydrogen peroxide, betadine, and saline.

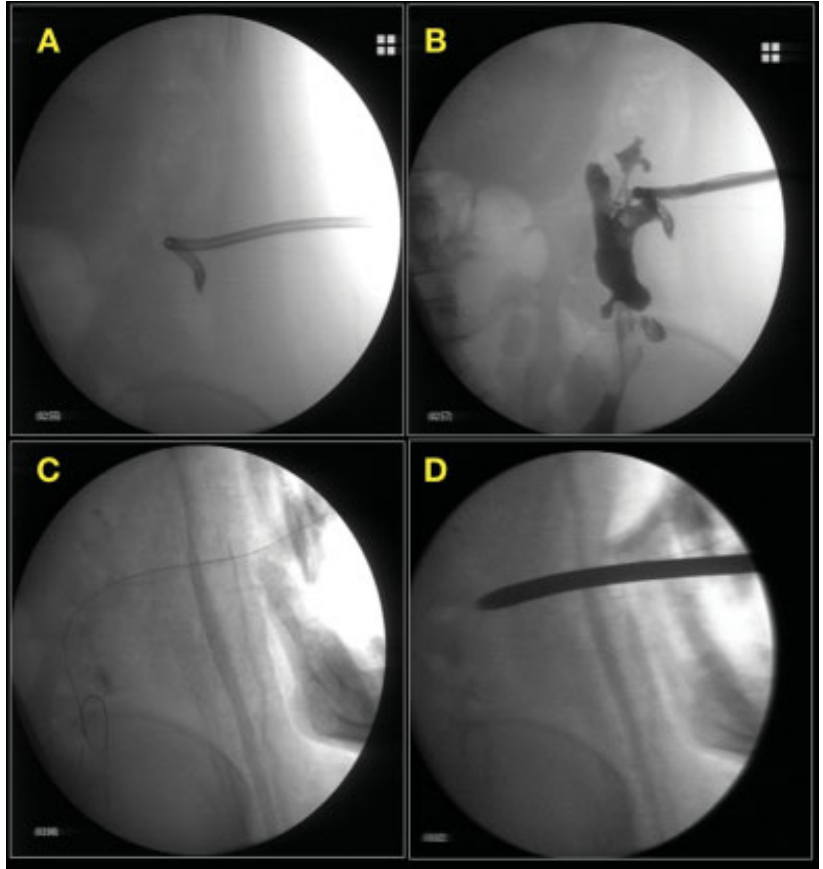

Fig. 2 Fluoroscopy images. (A) Percutaneous catheter drain (PCD) in situ for drainage of paracolic collection. (B) Contrast examination of paracolic cavity through PCD. (C) Guidewire passed into paracolic cavity through PCD. (D) Dilatation of percutaneous tract using $12 \mathrm{~mm}$ Hegar's dilator.

Interval CECT at 3 weeks revealed persistent residual lesser sac and significant paracolic collection with solid debris.

\section{Video 1}

Video demonstrating step-by-step technique of e-DEN and p-DEN for treatment of WOPN with paracolic extension. Online content including video sequences viewable at: https://www.thieme-connect.com/ products/ejournals/html/10.1055/s-0041-1741388.

Interdisciplinary consultation was sought from interventional radiology and surgery teams. The consensus was that

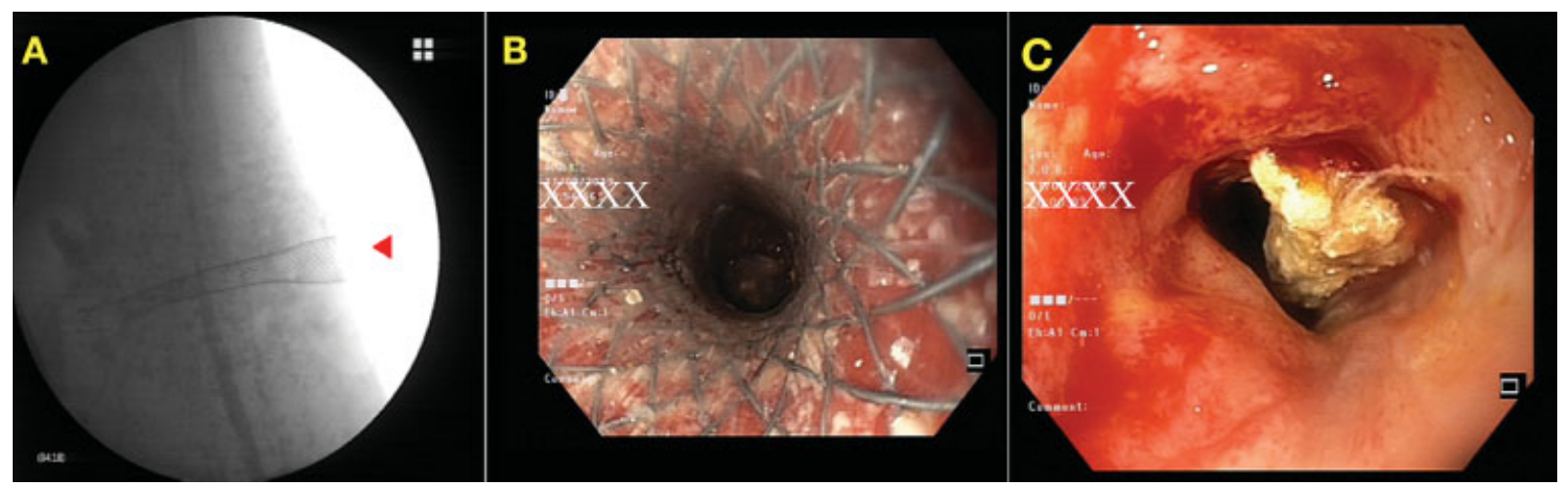

Fig. 3 (A) Deployed percutaneous esophageal fully covered self-expandable metal stent (FCSEMS) seen on fluoroscopy image (red arrow). (B) Endoscopic view through the percutaneous esophageal FCSEMS. (C) Solid debris seen in paracolic gutter collection. 
the paracolic gutter collection was contributing to the persistent symptoms and required effective drainage. Due to the irregular paracolic cavity with multiple side extensions, VARD was unlikely to be effective and open surgery was considered too morbid. A decision for p-DEN was therefore agreed upon.

The PCD track was dilated to $12 \mathrm{~mm}$ using Hegar's dilators (-Fig. 2) and an esophageal fully covered SEMS (FCSEMS) (Wallflex $18 \times 100 \mathrm{~mm}$; Boston Scientific Corporation, USA) was placed over the guidewire into the cavity to create an access port (-Video 1). A standard gastroscope was introduced through the stent into the cavity and DEN was performed (p-DEN) (-Fig. 3A-C). Additional e-DEN was performed through the transgastric route. Nasocystic drains were placed in both the collections for continuous saline irrigation of the cavities. A total of five DEN sessions (3 eDEN, 2 p-DEN) were required. LAMS was exchanged to multiple double pigtail plastic stents $(7 \mathrm{Fr} \times 3 \mathrm{~cm}) 3$ weeks after its placement ( - Fig. 4 ) and FCSEMS was exchanged to a 16 Fr PCD catheter after 5 days once paracolic cavity had collapsed. Interval CECT revealed near total resolution of WOPN (-Fig. 5). PCD was removed after 4 weeks. During the entire course of management, patient was maintained on intravenous antibiotics as per sensitivity patterns. Nutrition was maintained initially using a nasojejunal feeding tube and later by oral diet, and appropriate supportive care was prescribed as required. Total length of hospital stay was 39 days. At 8-week follow-up, patient was asymptomatic, was eating well, and had gained weight.

\section{Discussion}

This case presented a peculiar clinical dilemma. Our patient had persistent sepsis despite drainage of the lesser sac WOPN due to a paracolic gutter collection which defied PCD drainage. Given the ongoing sepsis, surgical necrosectomy could be considered as the next logical step of management. However, due to the issues mentioned earlier, VARD or

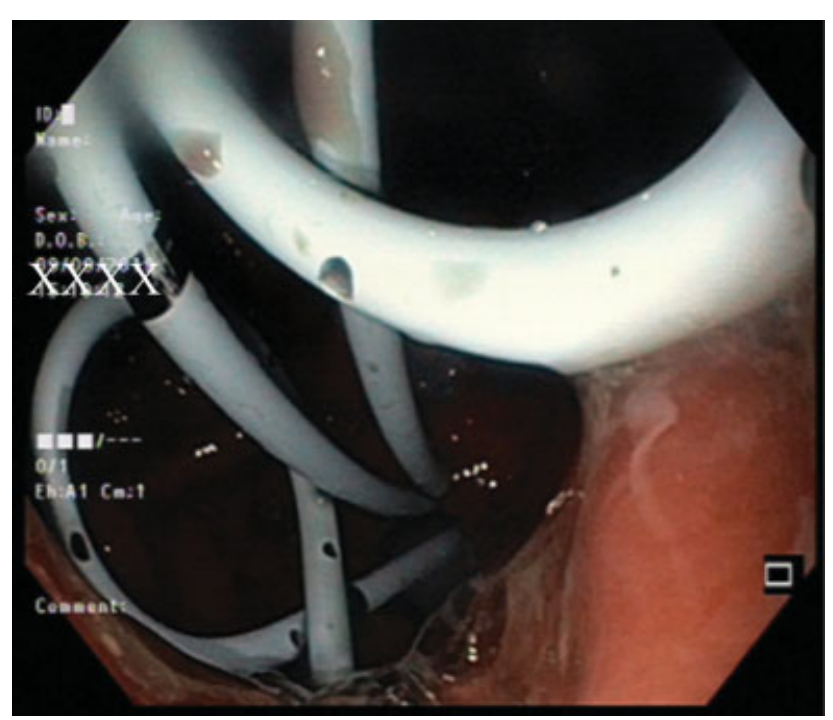

Fig. 4 Endoscopic view of multiple $7 \mathrm{Fr}$ double pigtail plastic stents placed via the transgastric cystogastrostomy after removal of the lumen-apposing metal stent (LAMS).

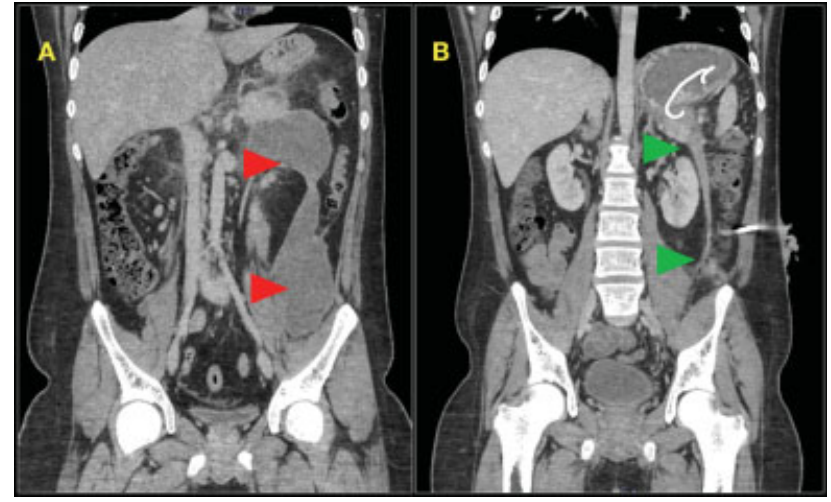

Fig. 5 Interval contrast-enhanced computed tomography (CECT) abdomen coronal section showing near complete resolution of walled-off pancreatic necrosis (WOPN) (B, green arrows) as compared with the index CECT ( $A$, red arrows).

surgical drainage was not considered optimal in our patient. A combined e-DEN and p-DEN approach has been infrequently described, although high technical and clinical success rates of 100 and 80 to $89 \%$, respectively, have been reported. ${ }^{2,3}$ We employed this combined approach in our patient with successful outcome. The advantage of such an approach is that the esophageal FCSEMS acts as an access port for passing the scope into the paracolic collection so that an effective DEN can be performed. This may obviate the need for formal VARD or surgical necrosectomy. By using a flexible endoscope, all side extensions and sinuses within the cavity can be effectively accessed. The FCSEMS can be easily removed once the cavity has collapsed. In our patient, a total of five DEN sessions (3 e-DEN, 2 p-DEN) were required.

In conclusion, this video case demonstrates successful management of a complex WOPN with paracolic extension using a combined e-DEN and p-DEN approach. Such an approach may help minimize or avoid surgical morbidity in appropriately selected patients.

Financial Disclosure

None.

\section{Consent}

Written informed consent was obtained from patient for publication of this report.

Conflict of Interest

None declared.

\section{References}

1 van Santvoort HC, Besselink MG, Bakker OJ, et al; Dutch Pancreatitis Study Group. A step-up approach or open necrosectomy for necrotizing pancreatitis. N Engl J Med 2010;362(16):1491-1502

2 Thorsen A, Borch AM, Novovic S, Schmidt PN, Gluud LL. Endoscopic necrosectomy through percutaneous self-expanding metal stents may be a promising additive in treatment of necrotizing pancreatitis. Dig Dis Sci 2018;63(09):2456-2465

3 Saumoy M, Kumta NA, Tyberg A, et al. Transcutaneous endoscopic necrosectomy for walled-off pancreatic necrosis in the paracolic gutter. J Clin Gastroenterol 2018;52(05):458-463 